\title{
Item Preview, Proficiency Level and Cognitive and Metacognitive Strategy Use in Multiple- choice Reading Comprehension Items
}

\author{
Amir Reza Nemat Tabrizi \\ Department of English language, Payame Noor University, I. R. of Iran \\ Saba Vafakhah (Corresponding author) \\ Department of English language, Payame Noor University, I. R. of Iran
}

\begin{abstract}
According to some studies, there can be a correlation between item preview, stem-option and stem, and test-takers' performance on a test. The present study was conducted to investigate the effect of test format on the strategy chosen by the testees in reading comprehension based on their level of proficiency. Three groups were selected based on the test-takers' performance on the TOEFL test, namely elementary, intermediate and advanced. Stem-option and stem were the methods applied to administer the main test. After administration of the TOEFL test, the interaction between the variables, item preview, test taking strategy and proficiency level, were investigated. It was assumed that use of specific strategies depends on the proficiency level and the item preview chosen as a method to administer the test. Results suggest that use of metacognitive strategy can be manipulated based on the testees' proficiency level and the item preview applied to administer a test, but there is not any interaction between item preview, proficiency level and application of cognitive strategies.
\end{abstract}

Index Terms - cognitive strategy use, metacognitive strategy use, stem preview, stem-option preview

\section{INTRODUCTION}

Reading comprehension is defined as "meaning-making process" which is done by application of some strategies (Zhang and $\mathrm{Wu}, 2009$ ). Kind of strategies taken by subjects to do the task at hand can change the result. According to some linguists (e.g. Phakiti, 2003), the strategies can be categorized into two kinds: cognitive and metacognitive. Cognitive strategies manipulate the material mentally or physically. Metacognitive strategies are applied to control comprehension and learning. The method applied to administer a test can lead subjects to choose specific strategies to take a test. Yanagawa and Green (2008) categorize the methods as follows: stem-option preview, stem preview and option preview. The item preview methods investigated in the present study are: stem option and stem. It is also assumed that the students' selection of strategy in different test methods is different based on their proficiency levels. It means that certain strategies are probably employed by students at particular proficiency levels under a specific method. If the assumption is supported, the most suitable test method can be selected based on the students' proficiency level. In other words, the method applied to administer a test can be selected based on the purpose of the test and the testees' proficiency level, so the evaluation can be more effective.

\section{A. Statement of the Problem}

Bachman (1990) argues that there are two systematic sources which lead to the variations in testees' performances: 1. Individuals' differences across their communicative language ability. 2. Differences across test formats, test methods and test tasks. A test has to be administered in a way that items of the test perform as the test developer intends them to perform. The item preview has to conform to a procedure by which the testees can be motivated to employ the language material that the test purports to measure. This study investigated the effect of the item preview on the students' testtaking strategy in reading comprehension test. As mentioned above, proficiency level can influence the strategy taken by the testees. So the other variable considered in the study is proficiency level of the participants. The test method variations investigated in the study are: 1 . Allowing test takers to preview both the item stems and options prior to reading 2 . Allowing test takers to preview only the item stems.

\section{B. Research Questions and Hypotheses}

Based on the different performances of testees at a multiple-choice reading comprehension test two questions can be evoked:

Q1. Is there any relationship between the type of item preview, cognitive strategy use and proficiency level?

Q2. Is there any relationship between the type of item preview, metacognitive strategy use and proficiency level?

Regarding the research questions mentioned above, the following research hypotheses can be proposed: 
H0-1. There is no relationship between the types of item preview, proficiency level and cognitive strategy use.

$\mathrm{H} 0-2$. There is no relationship between the types of item preview, proficiency level and metacognitive strategy use.

\section{Purpose of the Study}

Based on a variety of studies done on reading comprehension and the variables affecting the skill, three different variables were selected to be investigated. The relationship between the three variables, test taking strategy, proficiency level and item preview in reading comprehension has not been investigated up to now. Elementary, intermediate and advanced are the levels considered in this study. By application of verbal report an insight was provided into how test method or test format may affect learner responses and how these may interact with proficiency and test-taking strategy.

\section{Significance of the Study}

Ozuro, Y., Best R., Bell, C., Witherspoon, A. \& Mcnamara D. S. (2007) cite that effective assessment helps administrators know the testees' problems (Pellegrino, Chudowsky and Glaser, 2001). Therefore, it is critical to do research on reading comprehension assessment. To assess reading comprehension effectively, it is necessary to know restrictions related to the students because the situation and even the test structure can be manipulated based on the limitations. According to Phakiti (2003) the extent to which the application of the strategies in a reading comprehension test is similar to the real and natural use has to be clarified in order to reveal whether metacognitive strategy can be a source of measurement error or not; Messick (1996) called it as 'construct irrelevant' (cited in Phakiti, 2003). According to Cohen and Upton (2006), there are a lot of strategies employed by the test-takers, but some of the strategies were disturbing to the test validity. In fact, they were irrelevant to the task. Therefore, to improve test validity it is necessary to provide the respondents with some appropriate strategies rather than let them respond however they wish.

\section{The EFFect of Item PREVIEW ON TeSt-TAKing StRATEgIES}

Item preview has been investigated on multiple-choice listening comprehension by Yanagawa and Green (2008). They assert that there are three different test formats in multiple-choice listening comprehension. They say that the formats are such as: stem-option preview, option-preview and stem preview. The second format, option preview, has been rejected by the researchers. They assert that the second format causes more wrong answers than the other ones. Yanagawa \& Green also claim that there were no significant differences between stem and stem-option preview (2008). Yanagawa \& Green (2008) say that some researchers believe that stem preview makes test-takers ready to apply testtaking strategies more effectively (Littlewood, 1981; Ur, 1984; Mendelsohn, 1995; Buck, 1995; Thompson, 1995; Vandergrift, 1999). Yanagawa \& Green quote that based on Berne's investigation (1995) item preview helps the participants apply background knowledge relevant to the text effectively (2008). Yanagawa \& Green conclude that question preview can improve test-taking strategy and the planning before reading the existing text, but option preview may put a bigger burden on short-term memory. It is mentioned that test strategies are selected based on the test method or test format (Yanagawa \& Green, 2008). Cohen (1998) and Nevo (1989) state that, for example, in multiple-choice reading comprehension tests, lexical matching strategy is applied between answer options and the words existing in the text at hand because maybe there is a word/words in the option similar to a word in the text, or even perhaps the selected option had a word/words in the same word family as the word in the existing text, the choice can be because of existing a word in the option with the similar sound or meaning to a word in the text, and so forth (cited in Yanagawa \& Green, 2008). They drew the conclusion that the kind of available information before listening can influence the test performance. Freedle and Fellbaum (1987) believe that; besides item preview, proficiency level is the other factor that can affect the applied test-taking strategy. They say that low-proficiency participants apply lexical matching to find out similar words in the options or stems to the words in the text (cited in Yanagawa \& Green, 2008). After administration of a multiple-choice listening comprehension test, a verbal report developed by Wu (1998). He finds that item preview can improve and facilitate advanced listeners, but it can be problematic for less proficient listeners (cited in Yanagawa \& Green, 2008). Yanagawa \& Green conclude that the kind of test format influences test performance of the lowproficiency levels more than that of high-proficiency levels (2008). They state that contextualization of the questions can facilitate low-proficiency test-takers' performance, but the test-takers with higher proficiency can complete the task without the help of the questions (2008). The effects of stem preview on test performance have been investigated by Buck (1990, 1991) and Sherman (1997). They find out that there is not any significant relationship between stem preview and test performance or item difficulty (cited in Yanagawa \& Green, 2008).

\section{METHOD}

\section{A. Participants}

153 subjects were selected from among university students. The universities chosen were Islamic Azad universities of Islamshahr and Roudehen. The subjects' ages ranged from 20 to 24. The participants were majoring English Translation and English Literature. Before administration of the pre-test to determine the students' levels, the subjects were selected based on the term in which they were studying. The participants were selected from among Junior and 
senior students. They were expected to understand the TOEFL reading texts and questionnaire due to passing different courses on reading during their education. To get more exact information related to the students' levels, the scores got at the TOEFL exam, which was administered as a pre-test, were considered. The participants included both females and males.

\section{B. Instrumentation}

Two devices used in this study were: the TOEFL reading test and cognitive-metacognitive questionnaire. The questionnaire used in this study was proposed by phakiti (2006). Phakiti notes that the questionnaire was piloted to examine its reliability before the main administration. The other instrument used in the study was the TOEFL reading test taken from original TOEFL PBT which was administered in 2003 (Ebteda publication, 2005). The test consisted of three texts with 25 reading comprehension questions and 40 structure questions. The test was applied to determine the subjects' levels. For the main test, original sample of TOEFL PBT (2004) was selected (Ebteda publication, 2005). This test was composed of five texts, it contained 50 questions. The time allocated to the test was regularized based on the original test which was 55 minutes.

\section{Procedure}

At first, The original TOEFL reading comprehension test, composed of 40 structure questions and three passages with 25 questions, was applied to assign the participants' levels. The test was administered to 153 students. Then, their levels were determined based on their scores at the test. To identify elementary, intermediate and advanced subjects, the mean score of the subjects was calculated. The students whose scores fell at 0.5 SD above and 0.5 SD below the mean were considered as intermediate students, the subjects with the scores more than +0.5 SD were assigned as advanced participants and the testees with less than -0.5 SD were considered as elementary subjects. So there were three groups: elementary, intermediate and advanced.

TABLE 1

DESCRIPTIVE STATISTICS

\begin{tabular}{|l|l|l|l|l|l|}
\hline & $\mathrm{N}$ & Minimum & Maximum & Mean & Std. Deviation \\
\hline PROFICIENCY & 153 & 4.00 & 24.00 & 13.0784 & 5.27847 \\
Valid N (listwise) & 153 & & & & \\
\hline
\end{tabular}

There were 60 elementary, 48 intermediate and 45 advanced subjects. The participants were informed of the purpose of the study and a brief explanation was given to the students about the Likert-scales of the questionnaire. Dictionary use was not allowed. To administer the main test with two different item preview methods, the participants were divided into two groups. The groups had 90 and 63 students. As it was mentioned before, each of the groups was combination of the three elementary, intermediate and advanced levels. The first group had 36 elementary, 33 intermediate and 21 advanced participants. The second group had 24 elementary, 15 intermediate and 24 advanced subjects. An independent t-test was run to compare the Stem-Option and Stem groups' mean scores on proficiency test in order to prove that the two groups enjoyed the same level of general language proficiency prior to the main study. As displayed in Table 2, the mean scores for Stem-Option and Stem groups on proficiency test are 13.71 and 12.63 respectively.

TABLE 2

DESCRIPTIVE STATISTICS PROFICIENCY TEST STEM-OPTION AND STEM GROUPS

\begin{tabular}{|l|l|l|l|l|}
\hline Group & N & Mean & Std. Deviation & Std. Error Mean \\
\hline STEM-OPTION & $\mathbf{6 3}$ & $\mathbf{1 3 . 7 1 4 3}$ & $\mathbf{6 . 0 1 7 2 6}$ & $\mathbf{. 7 5 8 1 0}$ \\
\hline STEM & $\mathbf{9 0}$ & $\mathbf{1 2 . 6 3 3 3}$ & $\mathbf{4 . 6 7 7 1 0}$ & .49301 \\
\hline
\end{tabular}

The results of the independent $\mathrm{t}$-test $(\mathrm{t}(111)=1.19, \mathrm{P}=.234>.05$ indicate that there is not any significant difference between Stem-Option and Stem groups on proficiency test.

TABLE 3

INDEPENDENT T-TEST PROFICIENCY TEST STEM-OPTION AND STEM GROUPS

\begin{tabular}{|c|c|c|c|c|c|c|c|c|c|}
\hline & \multicolumn{2}{|c|}{$\begin{array}{l}\text { Levene's Test for } \\
\text { Equality of Variances }\end{array}$} & \multicolumn{7}{|c|}{ t-test for Equality of Means } \\
\hline & \multirow[t]{2}{*}{$\mathrm{F}$} & \multirow[t]{2}{*}{ Sig. } & \multirow[t]{2}{*}{$\mathrm{T}$} & \multirow[t]{2}{*}{$\mathrm{Df}$} & \multirow[t]{2}{*}{$\begin{array}{l}\text { Sig. (2- } \\
\text { tailed) }\end{array}$} & \multirow[t]{2}{*}{ Mean Difference } & \multirow[t]{2}{*}{$\begin{array}{l}\text { Std. Error } \\
\text { Difference }\end{array}$} & \multicolumn{2}{|c|}{$\begin{array}{l}95 \% \text { Confidence Interval of } \\
\text { the Difference }\end{array}$} \\
\hline & & & & & & & & Lower & Upper \\
\hline $\begin{array}{l}\text { Equal variances } \\
\text { assumed }\end{array}$ & 9.241 & .003 & 1.249 & 151 & .214 & 1.08 & .865 & -.629 & 2.79 \\
\hline $\begin{array}{l}\text { Equal variances not } \\
\text { assumed }\end{array}$ & & & 1.195 & 111.62 & .234 & 1.08 & .904 & -.710 & 2.87 \\
\hline
\end{tabular}

It should be noted that the assumption of homogeneity of variances is not met (Levene's $\mathrm{F}=9.24, \mathrm{P}=.003<.05$ ). That is why the first row of Table 3, i.e. "Equal variances assumed" is reported. 


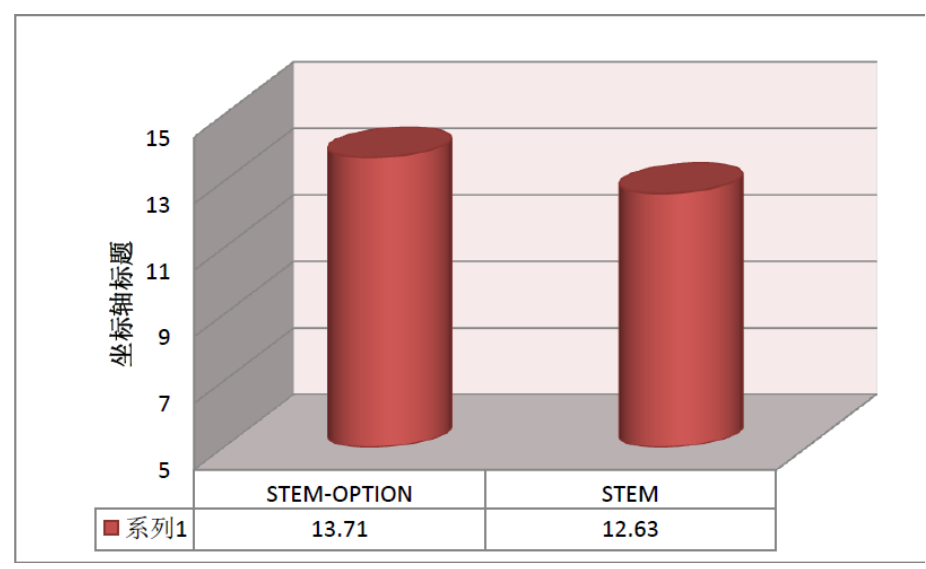

Figure 1: Proficiency Test Stem-Option and Stem groups

The TOEFL test composed of five passages with 50 questions was administered to one of the groups with stemoption preview; in other words, the group comprised of 63 subjects was allowed to have both stem and options of the tasks before reading the text. But the other group comprised of 90 participants just had stems at hand before reading the text. The first administration is typical in Iran. To administer the test with the second method each text was given to the participants just with stems; therefore, at first they were not provided with options. As it was mentioned above, the test had 50 questions. The time allocated to the test was regularized based on the original test time, so it was 55 minutes; hence, the suitable time for each of the texts was about 12 minutes. In the second administration, after reading each text and its stems in about 8 minutes, the options were provided too, so the subjects had almost 4 minutes to choose the best option which could be as the correct answer. After 12 minutes, another text was given to the students, so the test was administered in this way to the end. Immediately after the test administration, the questionnaire was administered to the testees to refer to what they did to complete the test. The answer sheets were scored in this way: each correct answer had one value. After calculating the scores, the international score chart was used to assign the test takers' real scores out of 30. The questionnaire was also scored based on the Likert-scale numbers chosen for the available items. To answer the questions of the study, two-way ANOVA was used. The statistical design used in this study is ex post-facto.

\section{Data AnALysis}

The instruments used in the study were the TOEFL reading comprehension test and a cognitive-metacognitive questionnaire. The study attempted to find out the effect of item preview on the testees' test-taking strategies based on the subjects' proficiency level. To achieve the goal of the study, the process of statistical procedures used in the study was explained in the following expressions. To investigate the test reliability, Kuder-Richardson 21 (KR-21) was used.

Analysis No.1: Is there any relationship between the type of item preview, cognitive strategy use and proficiency level?

Table 4 displays the descriptive statistics for the interaction between type of item preview and language proficiency on Cognitive Strategy Use.

TABLE 4

DESCRIPTIVE STATISTICS LANGUAGE PROFICIENCY AND TYPES OF ITEM PREVIEW COGNITIVE STRATEGY USE

\begin{tabular}{|c|c|c|c|c|c|}
\hline \multirow{2}{*}{ GROUP } & \multirow{2}{*}{ PROFICIENCY LEVEL } & \multirow[b]{2}{*}{ Mean } & \multirow[b]{2}{*}{ Std. Error } & \multicolumn{2}{|c|}{ 95\% Confidence Interval } \\
\hline & & & & Lower Bound & Upper Bound \\
\hline \multirow{3}{*}{ STEM-OPTION } & ELEMENTARY & 48.500 & 2.027 & 44.493 & 52.507 \\
\hline & INTERMEDIATE & 54.600 & 2.565 & 49.532 & 59.668 \\
\hline & ADVANCED & 47.000 & 2.027 & 42.993 & 51.007 \\
\hline \multirow{3}{*}{ STEM } & ELEMENTARY & 44.667 & 1.655 & 41.395 & 47.938 \\
\hline & INTERMEDIATE & 49.545 & 1.729 & 46.129 & 52.962 \\
\hline & ADVANCED & 46.286 & 2.167 & 42.002 & 50.569 \\
\hline
\end{tabular}

A two-way ANOVA was run to investigate the effect of the types of item preview, proficiency levels and their interaction on the students' cognitive strategy use.

TABLE 5

Two-WAy ANOVA COGNITIVE STRATEGy USE By TYPES OF ITEM PREVIEW AND PROFICIENCY LEVELS

\begin{tabular}{|c|c|c|c|c|c|}
\hline Source & $\begin{array}{l}\text { Type III Sum of } \\
\text { Squares }\end{array}$ & Df & Mean Square & $\mathrm{F}$ & Sig. \\
\hline GROUP & 360.585 & 1 & 360.585 & 3.655 & .058 \\
\hline PROFICIENCYLEVEL & 877.770 & 2 & 438.885 & 4.449 & .013 \\
\hline GROUP $*$ PROFICIENCYLEVEL & 110.442 & 2 & 55.221 & .560 & .573 \\
\hline Error & 14502.068 & 147 & 98.654 & & \\
\hline Total & 366510.000 & 153 & & & \\
\hline
\end{tabular}


The F-observed value for the effect of the types of the item preview is 3.65 (Table 5). This amount of F-value is lower than the critical F-value of 3.90 at 1 and 147 degrees of freedom. As displayed in Table 6, the mean scores for Stem-Option and Stem groups on cognitive strategy use are 50.03 and 46.83 respectively.

TABLE 6

DESCRIPTIVE STATISTICS OF TyPES OF ITEM PREVIEW ON COGNITIVE STRATEGy USE

\begin{tabular}{|l|l|l|l|l|}
\multicolumn{2}{l}{ DESCRIPTIVE STATISTICS OF TYPES OF ITEM PREVIEW ON COGNITIVE STRATEGY USE } \\
\hline \multirow{2}{*}{ GROUP } & & & \multicolumn{3}{l|}{$95 \%$ Confidence Interval } \\
\cline { 5 - 6 } & Mean & Std. Error & Lower Bound & Upper Bound \\
\hline STEM-OPTION & 50.033 & 1.282 & 47.499 & 52.567 \\
\hline STEM & 46.833 & 1.076 & 44.705 & 48.960 \\
\hline
\end{tabular}

The F-observed value for the effect of the proficiency levels is 4.44 (Table 5). This amount of F-value is higher than the critical F-value of 3.05 at 2 and 147 degrees of freedom. Based on these results it can be concluded that there are significant differences between the elementary, intermediate and advanced groups' mean scores on the cognitive strategy use.

As displayed in Table 7 the mean scores for the advanced, intermediate and elementary groups on the cognitive strategy use are 46.64, 52.07 and 46.58 .

TABLE 7

DESCRIPTIVE STATISTICS PROFICIENCY LEVELS ON COGNITIVE STRATEGy USE

\begin{tabular}{|c|c|c|c|c|}
\hline \multirow{2}{*}{ PROFICIENCY LEVEL } & \multirow[b]{2}{*}{ Mean } & \multirow[b]{2}{*}{ Std. Error } & \multicolumn{2}{|c|}{$95 \%$ Confidence Interval } \\
\hline & & & Lower Bound & Upper Bound \\
\hline ELEMENTARY & 46.583 & 1.309 & 43.997 & 49.170 \\
\hline INTERMEDIATE & 52.073 & 1.546 & 49.017 & 55.129 \\
\hline ADVANCED & 46.643 & 1.484 & 43.710 & 49.575 \\
\hline
\end{tabular}

Although the F-value of 4.44 indicates significant differences between the mean scores of the three proficiency levels on the cognitive strategy use, the post-hoc Scheffe's tests must be run to locate the exact places of differences between the means of the three groups.

TABLE 8

POST-HOC SCHEFFE's TESTS COGNITIVE STRATEGY USE By PROFICIENCY LEVELS

\begin{tabular}{|c|c|c|c|c|c|c|}
\hline \multirow{2}{*}{ (I) PROFICIENCY LEVEL } & \multirow{2}{*}{ (J) PROFICIENCY LEVEL } & \multirow[b]{2}{*}{ Mean Difference (I-J) } & \multirow[b]{2}{*}{ Std. Error } & \multirow[b]{2}{*}{ Sig. } & \multicolumn{2}{|c|}{$95 \%$ Confidence Interval } \\
\hline & & & & & Lower Bound & Upper Bound \\
\hline \multirow{2}{*}{ ELEMENTARY } & INTERMEDIATE & $-4.9250^{*}$ & 1.92341 & .040 & -9.6814 & -.1686 \\
\hline & ADVANCED & -.4667 & 1.95871 & .972 & -5.3104 & 4.3770 \\
\hline INTERMEDIATE & ADVANCED & 4.4583 & 2.06097 & .100 & -.6382 & 9.5549 \\
\hline
\end{tabular}

A: There is a significant difference between the elementary $(\mathrm{M}=46.58)$ and the intermediate group $(\mathrm{M}=52.07)$ on the cognitive strategy use.

$\mathrm{B}$ : There is not any significant difference between the elementary $(\mathrm{M}=46.58)$ and the advanced group $(\mathrm{M}=46.64)$ on the cognitive strategy use.

$\mathrm{C}$ : There is not any significant difference between the intermediate $(\mathrm{M}=52.07)$ and the advanced group $(\mathrm{M}=46.64)$ on the cognitive strategy use.

Based on the information displayed in Table 8, it can be concluded that the proficiency levels have a significant effect on the performance of the students on the cognitive strategy use. The F-observed value for the interaction between the type of item preview and language proficiency is not significant. The F-value of .56 (Table 5) is lower than the critical F-value of 3.05 at 2 and 147 degrees of freedom. As displayed through Fig. 2 at all three proficiency levels, the stem-option preview group performed better on cognitive strategy use than the stem group; hence, lack of interaction between type of item preview and language proficiency on cognitive strategy use is supported. Based on these results it can be concluded that the null-hypothesis as there is no significant interaction between proficiency levels and types of item preview on cognitive strategy use is supported. 


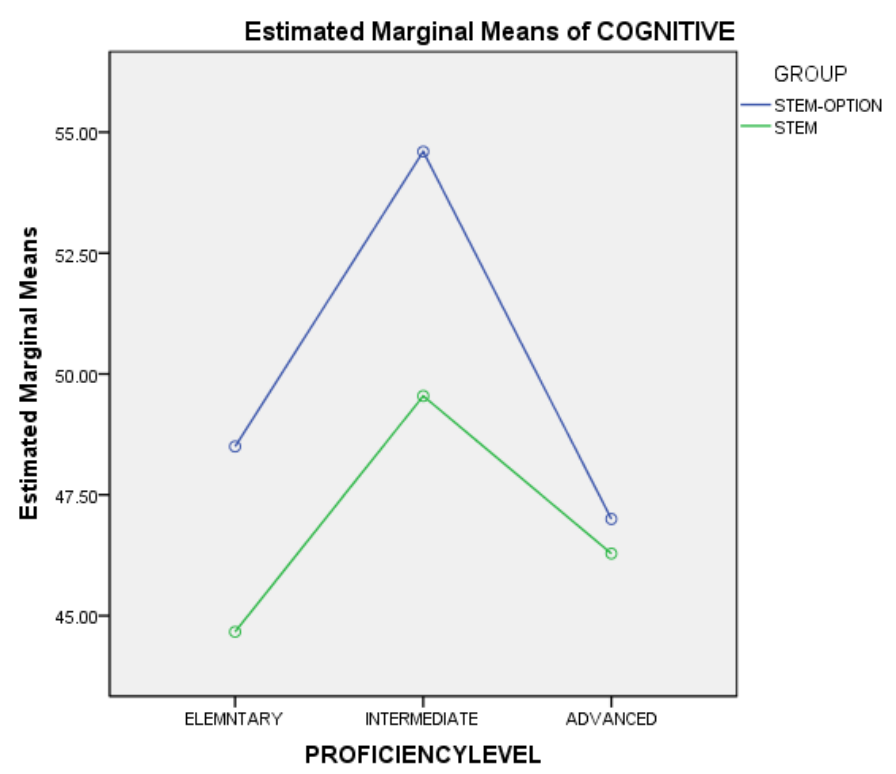

Figure 2: Lack of Interaction between Language Proficiency and Types of Item Preview on cognitive strategy use

Analysis No2: Is there any relationship between the type of item preview, metacognitive strategy use and proficiency level?

Table 9 displays the descriptive statistics for the interaction between type of item preview and language proficiency on metacognitive strategy use.

TABLE 9

DESCRIPTIVE Statistics LANGUAGE PROFICIENCY AND TYPES OF ITEM PREVIEW METACOGNITIVE STRATEGY USE

\begin{tabular}{|l|l|l|l|l|l|}
\hline \multirow{2}{*}{ GROUP } & PROFICIENCY LEVEL & \multirow{2}{*}{ Mean } & Std. Error & \multicolumn{3}{l|}{ 95\% Confidence Interval } \\
\cline { 4 - 6 } & & & & Lower Bound & Upper Bound \\
\hline \multirow{3}{*}{ STEM-OPTION } & ELEMENTARY & 49.250 & 2.211 & 44.880 & 53.620 \\
\cline { 2 - 6 } & INTERMEDIATE & 42.800 & 2.797 & 37.272 & 48.328 \\
\cline { 2 - 6 } & ADVANCED & 53.000 & 2.211 & 48.630 & 57.370 \\
\hline \multirow{3}{*}{ STEM } & ELEMENTARY & 41.833 & 1.806 & 38.265 & 45.402 \\
\cline { 2 - 6 } & INTERMEDIATE & 57.364 & 1.886 & 53.637 & 49.815 \\
\cline { 2 - 6 } & ADVANCED & 45.143 & 2.364 & 40.471 & \\
\hline
\end{tabular}

A two-way ANOVA is run to investigate the effect of the types of item preview, proficiency levels and their interaction on the students' metacognitive strategy use.

TABLE 10

Two-WAy ANOVA METACOGNITIVE STRATEGy USE BY TYPES OF ITEM PREVIEW AND PROFICIENCY LEVELS

\begin{tabular}{|l|l|l|l|l|l|}
\hline Source & $\begin{array}{l}\text { Type III Sum of } \\
\text { Squares }\end{array}$ & Df & Mean Square & F & Sig. \\
\hline GROUP & 1.972 & 1 & 1.972 & .017 & .897 \\
\hline PROFICIENCY LEVEL & 577.889 & 2 & 288.945 & 2.462 & .089 \\
\hline GROUP * PROFICIENCY LEVEL & 3615.385 & 2 & 1807.692 & 15.401 & .000 \\
\hline Error & 17254.108 & 147 & 117.375 & & \\
\hline Total & 384747.000 & 153 & & & \\
\hline
\end{tabular}

The F-observed value for the effect of the types of the item preview is .017 (Table 10). This amount of F-value is lower than the critical F-value of 3.90 at 1 and 147 degrees of freedom. Based on these results it can be concluded that there are not any significant differences between the Stem and Stem-option groups' mean scores on the metacognitive strategy use. As displayed in Table 11, the mean scores for Stem-Option and Stem groups on metacognitive strategy use are 48.35 and 48.11 respectively.

TABLE 11

DESCRIPTIVE STATISTICS TyPES OF ITEM PREVIEW ON METACOGNITIVE STRATEGY USE

\begin{tabular}{|l|l|l|l|l|}
\hline \multirow{2}{*}{ GROUP } & & & \multicolumn{3}{|l|}{$\mathbf{9 5 \%}$ Confidence Interval } \\
\cline { 5 - 6 } & Mean & Std. Error & Lower Bound & Upper Bound \\
\hline STEM & $\mathbf{4 8 . 3 5 0}$ & $\mathbf{1 . 3 9 9}$ & $\mathbf{4 5 . 5 8 6}$ & $\mathbf{5 1 . 1 1 4}$ \\
\hline
\end{tabular}

The F-observed value for the effect of the proficiency levels is 2.46 (Table 10). This amount of F-value is lower than the critical F-value of 3.05 at 2 and 147 degrees of freedom. Based on these results it can be concluded that there are not 
any significant differences between the elementary, intermediate and advanced groups' mean scores on the metacognitive strategy use. Thus proficiency levels do not have any significant effect on the performance of the students on the metacognitive strategy use. As displayed in Table 12 the mean scores for the advanced, intermediate and elementary groups on the metacognitive strategy use are 49.07, 50.08 and 45.54.

TABLE 12

DESCRIPTIVE STAtiSTICS PROFICIENCY LEVELS ON METACOGNITIVE STRATEGy USE

\begin{tabular}{|c|c|c|c|c|}
\hline \multirow{2}{*}{ PROFICIENCY LEVEL } & \multirow[b]{2}{*}{ Mean } & \multirow[b]{2}{*}{ Std. Error } & \multicolumn{2}{|c|}{$95 \%$ Confidence Interval } \\
\hline & & & Lower Bound & Upper Bound \\
\hline ELEMENTARY & 45.542 & 1.428 & 42.721 & 48.363 \\
\hline INTERMEDIATE & 50.082 & 1.687 & 46.748 & 53.415 \\
\hline ADVANCED & 49.071 & 1.619 & 45.873 & 52.270 \\
\hline
\end{tabular}

The F-observed value for the interaction between the type of item preview and language proficiency is significant. The F-value of 15.40 (Table 10) is higher than the critical F-value of 3.05 at 2 and 147 degrees of freedom. As displayed through Fig. 3, the elementary and advanced students applied more metacognitive strategies when they were provided with stem-options while the intermediate students took more metacognitive strategies when they were provided with stems only. Based on these results it can be concluded that the null-hypothesis as no significant interaction between proficiency levels and types of item preview on metacognitive strategy use is rejected.

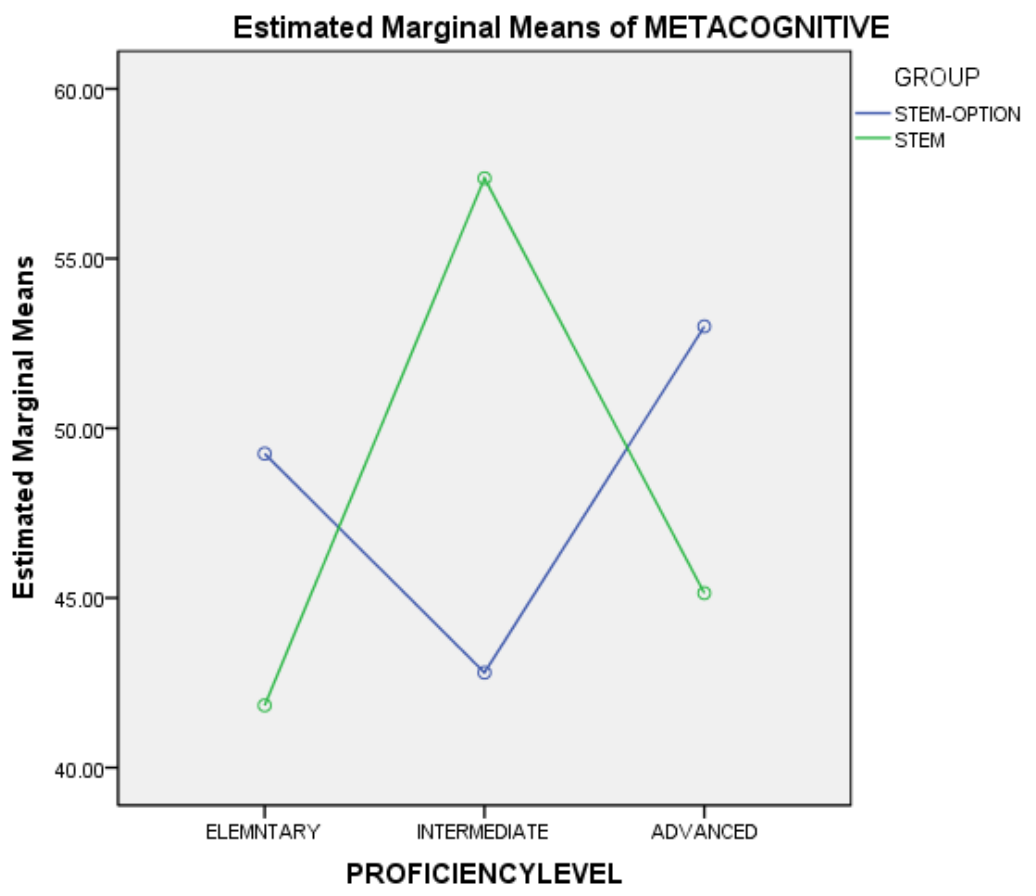

Figure 3: Significant Interaction between Language Proficiency and Types of Item Preview

\section{CONCLUSION}

In this study the interaction between item preview, stem and stem-option, proficiency level and test-taking strategy has been investigated. According to Kozo Yanagawa and Anthony Green (2008), in multiple-choice listening items changing of the order of the representation of the elements in an item can influence the nature of the task. They concluded that manipulating item format leads to lower performance if the students were provided with just options, but there were not any significant differences between the performances in the tests with stem and stem-option preview. But they quoted that stem preview can lead testees to apply strategies effectively (Littlewood, 1981; Ur, 1984; Mendelsohn, 1995; Buck, 1995; Thompson, 1995; Vandergrift, 1999). There were not any significant differences between the Stem and Stem-Option groups' use of cognitive and metacognitive strategies in the present study. But considering proficiency levels make the result quite different. Kind of item preview can affect the performance of the intermediate testees on the metacognitive strategy use. It means that intermediate stem group out-performed the intermediate stem-option group on metacognitive strategy use. Based on the result, stem preview can lead intermediate testees to apply metacognitive strategies more than the intermediate testees in the stem - option group. Therefore, to increase intermediate testees' use of metacognitive strategy, stem preview method can be selected. But for the other levels, elementary and advanced, providing stem-option method can lead them to take more metacognitive strategies. Due to the results, the students can be provided with a situation in which the appointed strategy can be taken. In other words, a list of useful and suitable 
strategies can be prepared based on the students' levels. The list can help testees apply the strategy that makes the exam result higher. Walter (2007) also states that teachers can introduce appropriate strategies to readers. He also quoted that teachers can guide the readers how to select an appropriate strategy and how to use strategies selectively (Alderson, 1991). Generally, Reading comprehension is a skill which can be improved by manipulating the kind of item preview chosen to administer a test. An instructor can motivate students to choose certain strategies based on the purpose of the exam and level of the students.

\section{REFERENCES}

[1] Bachman, L. F. (1990). Fundamental consideration in language testing. New York: Oxford University Press.

[2] Cohen, A. D. \& Upton, T. A. (2006). Strategies in Responding to the New TOEFL Reading Tasks. Educational Testing Service (ETS). http://www.ets.org/Media/Research/pdf/RR-06-06.pdf (accessed: 5/5/2011).

[3] Ozuro, y., Best r., Bell, c., Witherspoon, a. \& Mcnamara d. s. (2007). Influence of question format and text availability on the assessment of expository text comprehension. Cognition and Instruction, 25, 399-438.

[4] Phakiti, A. (2003). A closer look at the relationship of cognitive and metacognitive strategy use to EFL reading achievement test performance. Language Testing 20, 26-56.

[5] Phakiti, A. (2006). Modeling cognitive and metacognitive strategies and their relationships to EFL reading test performance. Melbourne Papers in Language Testing, 1, 53-95.

[6] Phakiti, A. (2006). Theoretical and pedagogical issues in ESL/EFL teaching of strategic reading. University of Sydney Papers in TESOL, 1, 19-50.

[7] Walter, H. C. (2007). First to second language reading comprehension. Applied Linguistics, 17, 14-37.

[8] Yanagawa, k. \& Green, A. (2008). To show or not to show: The Effects of Item Stems and Answer Options on Performance on a Multiple-Choice Listening Comprehension Test. System, 36, 107-122.

[9] Zhang, L. J. \& Wu, A. (2009). Chinese senior high school EFL students' metacognitive awareness and reading-strategy use, Reading in a Foreign Language, 21, 37-59.

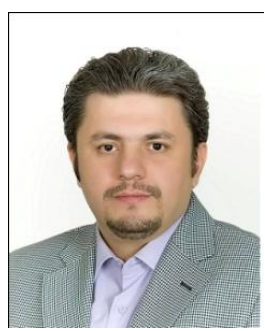

Amir Reza Nemat Tabrizi was born in Tehran, Iran on January 21,1971. He has a Ph.D. in tefl from university of Panjab ,India in 2009, his MA in tefl from Islamic Azad University of Tehran, Iran in 2003 and BA in English literature from Islamic Azad University of Tabriz, Iran in 1998.

$\mathrm{He}$ is a professor in Payame Noor University of Tabriz, Iran. He has also worked in Islamic Azad University of Roudehen, Iran, Islamic Azad University of Karaj, Iran and Payame Noor University of Tehran, Iran. His articles published are such as: Language Proficiency and Critical Thinking, Chandigarh, India: Divine journal , 2007. Discourse Analysis and English Language Teaching, Chennai, India: CETEFL, 2007. There are some books published in Iran: English for the Students of Mechanization and Mechanics of Agricultural Machinery, Tehran, Iran:Samt, 2004 and Basic Reading Selections, Tabriz, Iran: Pardazesh, 2007.

Dr. Tabrizi was a member of TELLSI (Teaching English Language and Literature Society of Iran).

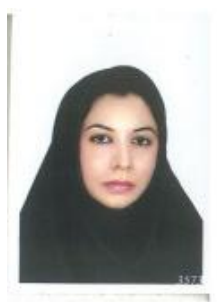

Saba Vafakhah was born in Broujerd, Iran on September 18, 1984. She received her MA in tefl from Payame Noor University in Tehran, Iran in 2011 and her BA in English translation from Arak university in Arak, Iran in 2003.

She is a Teacher in the foreign language institute of Tehran university in Tehran, Iran. She has also worked in Iranmehr (NBE) institute, Tarasht plant, Literature faculty of Tehran University. 